\title{
INTELIGÉNCIA COMPETITIVA: UMA REVISÃO DE LITERATURA
}

\section{Estera Muszkat Menezes}

\section{Resumo}

Revisão de literatura sobre inteligência competitiva, levantada no Library \& Information Science Abstracts (LISA) do período de 1969 a 2004, priorizando as publicações nacionais da área da Ciência da Informação e como estrangeira a Business Information Review, complementando com algumas publicações, não indexadas no LISA, porém relevantes na área.

\section{Palavras-chave}

Inteligência competitiva; Ciência da informação.

\section{COMPETITIVE INTELLIGENCE: LITERATURE REVIEW}

\begin{abstract}
Literature review on competitive intelligence, searched in the Library \& Information Science Abstracts (LISA), since 1969 to 2004, giving emphasis to national Journals on Science Information and as major foreign publication, the Business Information Review, complemented with relevant but not indexed publications in LISA.
\end{abstract}

\section{Keywords}

Competitive intelligence; Science information. 


\section{INTRODUÇÃO}

Este artigo apresenta uma revisão de literatura sobre Inteligência competitiva. Essa revisão foi levantada no Library \& Information Science Abstracts (LISA) do período de 1969 a 2004, período de abrangência do mesmo.

O LISA é editado pela Cambridge Scientific Abstracts e publicado pelo National Information Services Corporation (NISC), e é o melhor recurso conhecido de pesquisa na área de Ciência da Informação. Seus resumos cobrem os assuntos sobre: Inteligência Artificial, Administração de Bibliotecas, Administração de Informação, Administração de Registros, Administração do Conhecimento, Aplicações de Informática, Biblioteca, uso e usuários, Bibliotecas e Arquivos, Biblioteconomia, CD-ROMs, Centros de Informação, Ciência da Informação, Informação Médica, Recuperação da Informação on-line, Tecnologia bibliotecária, Tecnologia da Internet, Tecnologia da Informação, Telecomunicações, World Wide Web.

Foram incorporados novos enfoques temáticos importantes na estratégia de cobertura do LISA para atender e ajudar a refletir sobre os novos padrões sociais junto as mudanças requeridas na Biblioteca e no campo da Ciência da Informação, são eles: Administração de sistemas de Informação, Ensino da Informação e temas gerenciais. Contém mais de 215.000 registros, em mais de 20 línguas, de 550 periódicos, de 68 países. Sua atualização é mensal e é disponibilizado on-line e em CD-ROM.

Optou-se pelo LISA por ser uma base de dados onde são indexados a maioria dos periódicos da Ciência da Informação. Mas, também fez - se um levantamento em três publicações periódicas disponibilizadas on-line com grande representação na área de Ciência da Informação, sendo elas:

Encontros Bibli: Revista Eletrônica de Biblioteconomia e Ciência da Informação, publicada pelo Departamento de Ciência da Informação, em conjunto com o Programa de Pós- Graduação em Ciência da Informação da Universidade Federal de Santa Catarina, esta revista é indexada em Red de Revistas Cientificas de América Latina y El Caribe, Espanã y Portugal (RedALyC) e no Sistema Regional de Información en Linea para Revistas Científicas de América Latina, El Caribe, Espanã y Portugal(LATINDEX), disponibilizada on-line (http://www.encontrosbibli.ufsc.br/), desde maio 1996. É uma publicação semestral, recebe artigos inéditos de 
Biblioteconomia e Ciência da Informação, de caráter opinativo, fundamentados em revisão de literatura ou de caráter científico, fundamentados em pesquisas e/ou relatos de experiências. A publicação DataGramaZero: Revista de Ciência da Informação é uma revista do Instituto de Adaptação e Inserção na Sociedade da Informação (IASI ).O IASI é uma organização nãoovernamental estabelecida no Rio de Janeiro, RJ, Brasil sem qualquer vinculação políticopartidária ou religiosa, e dedicada a estudos e pesquisas sobre Sociedade da Informação. Estabelecida em novembro de 1998, disponibilizada on-line (http://www.dgz.org.br) a partir de dezembro de 1999 com periodicidade bimensal, cada edição da DataGramaZero se propõe reunir textos, por afinidade temática, destinados às seções de artigos, comunicações e recensões visando divulgar e promover perspectivas críticas fundamentadas em áreas interdisciplinares da Ciência da Informação, tais como Informação e Sociedade, Informação e Políticas Públicas, Informação e Filosofia ou Informação e Comunicação e na Revista Digital de Biblioteconomia e Ciência da Informação (http://server01.bc.unicamp.br/seer/ojs/), publicada a partir julho de 2003 , é uma publicação eletrônica com periodicidade semestral do Sistema de Bibliotecas da UNICAMP, abrangendo áreas temáticas encontradas na Biblioteconomia e Ciência da Informação, indexada na base Edubase e Latindex. Assim como, pesquisou-se na revista Transinformação (http://www.puccamp.br/ biblio) editada pelo Departamento de Pós-graduação da Faculdade de Biblioteconomia da Pontifícia Universidade Católica de Campinas, porém poucos números estão disponibilizados.

Quanto à publicação estrangeira analisou-se a Business Information Review, que é uma publicação inteiramente voltada para informação internacional de negócios, inclui assuntos voltados para os profissionais da Biblioteconomia e Ciência da Informação, faz análise profunda de todos os tipos e serviços de informação para negócios incluindo livros de referência, base de dados on-line, serviços de informação e de indexação, pesquisas originais sobre serviços e aplicações para informação de negócios. Essa publicação é editada pelo Bowker-Saur, é quadrimestral, desde 1993. Esta revisão inicia-se com alguns conceitos de inteligência competitiva, onde buscou-se na literatura alguns autores, que ajudaram no costuramento do tema.

No conteúdo básico da revisão, priorizou-se as publicações periódicas por entender, que essas trazem informações mais recentes e a princípio de acesso mais amplo. 


\section{METODOLOGIA}

Realizou-se a pesquisa na base de dados do LISA, tomando como palavra chave, o descritor “Competitive intelligence”. Foram listados 150 artigos, de diversos periódicos indexados pelo LISA. Essa listagem, foi checada, na Biblioteca Setorial do Centro de Ciências da Educação da Universidade Federal de Santa Catarina(BS-CED/UFSC) e no Portal da CAPES (via BU/UFSC) para verificar a existência da coleção completa do periódico, a fim de poder recuperar os artigos na íntegra sobre o assunto selecionado.

Das publicações nacionais, atualmente indexadas nesta base recuperou-se todos os artigos, sendo da Ciência da Informação, revista que é publicada quadrimestralmente (online através do sitio $\underline{w w w . i b i c t . c o m . b r / c i o n l i n e ~}$ ou www.scielo.br) pelo Instituto Brasileiro de Informação em Ciência e Tecnologia - IBICT, órgão do Conselho Nacional de Desenvolvimento Científico e Tecnológico - CNPq do Ministério da Ciência e Tecnologia - MCT. Essa revista destina-se à publicação de trabalhos originais relacionados com a Ciência da Informação ou que apresentem resultados de estudos e pesquisas sobre as atividades do setor de informação, tanto bibliográfica quanto não bibliográfica, em ciência e tecnologia, tem seus artigos também indexados ou resumidos nas bases Paschal Thema: Science de L' Information, Documentation ,PAIS Foreign Language Index, Information Science Abstracts Library and Literature, Páginas de Contenido: Ciencias de la Información, Educacción: Notícias de Educación, Ciencia y Cultura Iberoamericanas e Referativnyi Zhurnal: Informatika. Foram encontrados 17 artigos de 1993 a 2004, assim distribuídos: 1993(1), 1997(2), 1999 (7), 2000(2), 2001(1), 2002(1), 2003(3).

Do periódico Informação \& Sociedade: Estudos, disponibilizado online (www.informacaoesociedade.ufpb.br) de 1991 a 2004 publicação do Mestrado em Biblioteconomia da Universidade Federal da Paraíba dois artigos foram encontrados; um de 1992 e um de 1999. A Revista de Biblioteconomia de Brasília, publicada pela Associação dos Bibliotecários do Distrito Federal e Departamento de Biblioteconomia da Faculdade de Estudos Sociais Aplicados da Universidade de Brasília, teve inicio em 1973, com periodicidade semestral até 1990. De 1991 a 1994 foi temporariamente suspensa. Consta em suas publicações a indexação no LISA, mas na busca nenhum artigo foi registrado sobre o tema. Fazendo uma busca 
retrospectiva dos fascículos disponíveis na Biblioteca Setorial do CED, encontrou-se um número especial de 1999/2000, com 5 artigos e 3 comunicações sobre Inteligência competitiva, os quais foram incluídos na revisão. Assim como a publicação da revista Perspectiva em Ciência da Informação, publicação da Escola de Biblioteconomia da Universidade Federal de Minas Gerais, desde 1996, que é continuação da Revista da Escola de Biblioteconomia da UFMG(1972-1995), é uma publicação semestral e consta que é indexada no LISA, sendo que na busca nada encontramos, mas na conferência em papel na BS-CED/UFSC encontramos um artigo de 2000 e incluímos nesta revisão.

Das publicações não indexadas, porém relevantes fizemos a busca nos 18 números do Encontros Bibli: Revista Eletrônica de Biblioteconomia e Ciência da Informação disponibilizados de maio de 1996 ao segundo semestre de 2004 onde encontramos 5 artigos na edição especial do primeiro semestre de 2004.

Assim também, fêz-se uma busca nos 20 números disponibilizados no DataGramaZero: Revista de Ciência da Informação, de dezembro de 1999 a dezembro de 2004 onde capturou-se 8 artigos, sendo de 2001(4), 2002 (2) , 2003 (1) e 2004 (1). O periódico Transinformação, com periodicidade quadrimestral a partir de janeiro de 1989, dois artigos de 1999 e um em 2001, foram recuperados e inseridos nesta revisão. Na publicação da Revista Digital de Biblioteconomia e Ciência da Informação, até o final da pesquisa nada foi encontrado.

Dos periódicos estrangeiros listados no LISA, a coleção mais completa disponível na BS-CED/UFSC, foi a Business Information Review de 1993 à 1999, onde recuperou-se apenas 3 artigos, sendo 1997(1) e 1999(2).

\section{INTELIGÊNCIA COMPETITIVA}

Com o avanço tecnológico na parte da informática, com o surgimento da Internet, das tecnologias da informação, houve uma explosão da documentação. A quantidade de dados disponíveis em suporte digital aumentou, tornando-se mais fácil o acesso. Com a globalização muitas pessoas

(C) Revista Digital de Biblioteconomia e Ciência da Informação, Campinas v.3, n. 1, p. 103-130, jul./dez. 2005 - ISSN: 1678-765X. 
passaram a compartilhar e a ter acesso as mesmas informações, passou-se a ser a 'sociedade da Informação'.

Sociedade da informação é basicamente a economia alicerçada na informação e na telemática, ou seja, informação, comunicação, telecomunicação e tecnologia da informação (VALENTIM, 2002).

Buscou-se em alguns livros, autores que abordam sobre a inteligência competitiva, onde abaixo passa-se a parafrasear as sua idéias.

Tarapanoff (2001) defende que a gestão da informação e do conhecimento, bem como a inteligência competitiva, constituem, do ponto de vista teórico, uma nova metodologia, uma nova abordagem e síntese teórica, para o planejamento e administração estratégica das organizações e para a sua tomada de decisão.

O trabalho e o capital são recursos de uma organização, assim como também é o conjunto de dados e informações que uma empresa possui, mas estes passam a ser relevantes quando agregam valor à organização.

Segundo Porter (1986) a leitura dos sinais do mercado exige técnicas. É preciso determinar uma metodologia para a decisão sobre quais são os dados particularmente cruciais e sobre o modo como eles podem ser analisados.

Naisbitt e Aburdene (1985) procuraram mostrar a utilização e a influência da informação, também, nas organizações, apontando a alta dependência das redes e das tecnologias da informação.

A informação passa a ter valor quando analisada, tratada, disseminada e direcionada à pessoa certa, na hora certa.

(C) Revista Digital de Biblioteconomia e Ciência da Informação, Campinas v.3, n. 1, p. 103-130, jul./dez. 2005 - ISSN: 1678-765X. 
Comb e Moorhead (1993) compreendem a inteligência competitiva como a seleção, coleção, interpretação e distribuição da informação publicamente segura que possui importância estratégica. Dentre suas principais metas destacam: detectar ameaças competitivas, eliminar ou minimizar surpresas, acrescentar vantagem competitiva minimizando o tempo de reação e encontrar novas oportunidades.

Segundo Martinet e Marti (1995) a inteligência competitiva começou a ser adotada nas décadas de 70-80, intensificando-se na década de 90 e deve alcançar sua maturidade no início do século XXI e tem como principal função suprir as organizações de informações, a fim de prepará-las para a concorrência e a globalização dos mercados.

Para Jacobiak (1996) a inteligência competitiva pode ser considerada uma parte significativa da gestão estratégica da organização, por meio da informação que permita aos tomadores de decisão se anteciparem sobre tendências dos mercados e posição dos concorrentes.

Conforme Kahaner (1996), a inteligência competitiva é um processo institucional sistemático para garimpar e analisar informação sobre as atividades da concorrência e as tendências do setor específico e do mercado em geral, com o propósito de levar a organização a atingir seus objetivos e metas.

Segundo Tyson (1998) a inteligência competitiva é um processo analítico que envolve informações sobre todas as organizações e eventos do meio externo que são importantes à organização, causando algum tipo de impacto. A inteligência está em transformar informações dispersas em conhecimento estratégico para a organização.

Prahalad e Krishnam (1999) apontam a necessidade da organização manter um aprimoramento contínuo para contar com a confiabilidade de respostas às oportunidades e ameaças, com capacidade de adaptação e inovação rápida, dependem de uma infra-estrutura da informação de alta qualidade.

(C) Revista Digital de Biblioteconomia e Ciência da Informação, Campinas v.3, n. 1, p. 103-130, jul./dez. 2005 - ISSN: 1678-765X. 
A inteligência competitiva age como um radar, monitorando o ambiente da organização na busca de informações valiosas à atividade estratégica, procura descobrir oportunidades e reduzir riscos ligados à incerteza.

\section{INTELIGÊNCIA COMPETITIVA E SUAS INTERFACES}

Apresenta-se uma retrospectiva que vai de 1992 a 2004 das diversas abordagens e recortes apresentadas por vários autores.

Tudor-Silovic (1992) discorre sobre o conceito de inteligência, voltada para o desenvolvimento econômico, inteligência como recurso social e empresarial. Inteligência, aqui usada tanto no sentido de descrever a capacidade mental de um indivíduo ou um grupo de indivíduos, como no sentido coletivo e organizacional, como estratégia para se atingir objetivos comuns. Faz uma abordagem inter e multidisciplinar que incorpora idéias, métodos e técnicas de diferentes campos, como da elaboração política, planejamento estratégico, tecnologias, estudos de desenvolvimento, economia, ciência comportamental entre outros. Enfatiza que quando se refere à inteligência, não se pode falar apenas de indivíduos inteligentes, mas também de empresas inteligentes e nações inteligentes.

Maury (1993) apresenta um estudo das estratégias de decisão desde a China Antiga, até a competitividade internacional. Faz uma leitura da função informação/inteligência como fator de estruturação da economia e de resolução dos impasses micro/macroeconômicos. Considera a inteligência competitiva como uma disciplina formada por múltiplas competências, que integra e desenvolve níveis de percepção racional e indutiva. O autor faz uma abordagem sobre a inteligência competitiva e qualidade total, onde expõe o caso da indústria automobilística Toyota, enfatizando a percepção antecipada e a implementação pioneira, que criou empiricamente as condições para o controle da qualidade total.

Pozzebon, Freitas, Petrini (1997) evidenciam a importância da integração de um módulo de inteligência competitiva, considerando a coleta, organização e difusão da informação externa, nos sistemas de informações para o apoio à decisão das empresas, enriquecendo assim o Enterprise Information Systems (EIS). Tendo como propósito maior fornecer um grande volume de 
informações, tanto externas quanto internas, formais e informais. Informações sobre as percepções do mercado, informações envolvidas em análises e simulações, propiciando um ambiente integrador das informações disponíveis e relevantes, procurando a identificação ou antecipação de problemas e oportunidades. Apresenta alguns conceitos de inteligência competitiva, assim como ferramentas utilizadas para a coleta de informações.

Cubillo (1997) apresenta algumas reflexões sobre a inteligência empresarial nas pequenas e médias empresas competitivas da América Latina, considerando-as úteis aos profissionais da região da América Latina e Caribe, envolvidos nos trabalhos de geração, processamento, comercialização e administração dos conhecimentos e das informações necessárias às pequenas e médias empresas. Apresenta o fluxo de conhecimento e informações tanto da grande, quanto da pequena empresa. Salienta no texto que esta é uma primeira abordagem ao tema inteligência aplicado ao mundo das pequenas e médias empresas, onde houve uma preocupação do relacionamento dos atores: os donos da empresa e os trabalhadores do conhecimento e da informação.

Simmons (1997) mostra algumas dicas para os analistas inteligentes de empresas (business intelligence analystis-BIAs) de como adquirir inteligência competitiva e a importância da Internet na coleta desta informação. Mas também chama a atenção para o perigo de confiar demais em World Wide Web e em serviços de alerta. Salienta a importância da informação relevante, precisa e no tempo correto sobre os concorrentes e que agrega valor a organização. Enfatiza que é a inteligência, e não a informação que dá suporte ao decisor sobre adequadas táticas de mercado ou decisão de longo prazo. Os BIAs são os “olhos e ouvidos” da organização. E o trabalho do BIA não é somente no escritório, ele deve ir a feiras, exposições e conferências relevantes, que são excelentes oportunidades de "espionar" os concorrentes.

Abreu, França, Sinzato (1999) mostram o uso e o diferencial de competitividade que a Tecnologia de Informação (TI) vem trazendo à área de pesquisa e desenvolvimento no Estado de Santa Catarina. Apresentam um estudo feito com cinco grupos que utilizam tecnologias de informação e que vêm se destacando no meio produtivo tecnológico, científico e de serviços, sendo eles: Empresa Brasileira de Compressores S.A (Embraco), de Joinville/SC; Centro 
Integrado de Metrologia e Recursos Hídricos de Santa Catarina (Climerh),da Empresa Catarinense de Pesquisa Agropecuária (Epagri), de Florianópolis/SC. E, três grupos de pesquisa da Universidade Federal de Santa Catarina, Florianópolis/SC: Grupo de Química Bioinorgânica do Departamento de Química/Centro de Ciências Físicas e Matemáticas, Grupo de Pesquisa em Farmacologia de Produtos Naturais e de Peptídeos Biologicamente Ativos do Departamento de Farmacologia/ Centro de Ciências Biológicas e o Departamento de Química/ Centro de Ciências Físicas e Matemáticas. Identificam usos estratégicos da TI e o diferencial competitivo decorrente destes usos nas organizações pesquisadas. Salientam que esse é o reflexo de uma nova forma de conectar pessoas e processos, pelo redesenho de funções e ambiente dentro e fora das organizações.

Tomimori (1999) apresenta uma avaliação da mudança de paradigma que está sendo implantada na atual gestão do Centro de Informação Tecnológica (Citec), do Instituto de Pesquisas Tecnológicas do Estado de São Paulo (IPT-SP). Busca demonstrar a atuação do profissional de informação como agente de mudança e as formas de como pode intervir na cultura da organização, dentro da nova estratégia do IPT, de compartilhamento dos riscos e benefícios do desenvolvimento tecnológico entre os setores produtivo privado e público. Salienta que nesse cenário, é indispensável que os profissionais que trabalham com a prestação de serviços de informação, atualizem seus conhecimentos e adaptem seus perfis de competência e habilidades às novas necessidades deste contexto. Essa nova visão da gestão da informação sob enfoque de modernos princípios envolvendo qualidade, competitividade e produtividade, aliados aos recursos tecnológicos, está fazendo do Citec uma organização baseada na informação e no conhecimento, priorizando o desenvolvimento científico e tecnológico do IPT e do país.

Silva (1999) inicia o artigo apresentando algumas definições divergentes de inteligência competitiva, inteligência sobre os competidores, inteligência corporativa, business intelligence, inteligência empresarial, inteligência econômica e o termo encontrado na literatura como mais geral é inteligência organizacional. Essa análise reflexiva partiu de dentro da literatura científica e corporativa sobre tecnologias de informação. O autor apresenta uma descrição dos métodos de trabalho e os resultados da Consultoria Biomundi, como centro de inteligência organizacional para a industria biofarmacêutica.

(C) Revista Digital de Biblioteconomia e Ciência da Informação, Campinas v.3, n. 1, p. 103-130, jul./dez. 2005 - ISSN: 1678-765X. 
A Consultoria Biomundi é composta por profissionais de formação básica em ciências farmacêuticas, biologia, química, medicina, direito, economia, ciências da informação, informática e telecomunicações. Que realmente trabalham em equipe. A Consultoria Biomundi conta com uma rede local de 42 terminais, conectados a rede pública de transmissão de dados, com saída internacional. Há um intercâmbio bibliotecário, dos documentos não oficiais, estes mantêm contato com os consultores cubanos, assim como da América Latina e Europa.

Freeman (1999) define os diferentes tipos de inteligência, informação e conhecimento, enfatizando a natureza indefinida dos limites e fronteiras. Apresenta exemplos de inteligência nos negócios financeiros e explica porque as habilidades de inteligência são essenciais para a sobrevivência dos negócios. Focaliza o que faz o bom analista de inteligência e discute se o software computacional pode produzir "inteligência" através da coleta de informação computadorizada. Ilustra a discussão com um estudo de caso sobre a coleta de informação utilizada no Midland Bank, na Inglaterra. Enfatiza a importância de contratações em companhias em crescimento e o papel da inteligência competitiva. Salienta ainda, que a inteligência só existe com a informação, mas a informação sozinha, não é inteligente!

Costa e Silva (1999) apresentam conceitos e objetivos sobre as informações publicadas requeridas pelo processo de inteligência competitiva, procurando caracterizar as informações. As informações são coletadas para o referido processo, a partir da metodologia de coleta e dos recursos informacionais propostos por Tyson. Discutem as fontes de informação publicadas e suas peculiaridades. Apresentam um quadro quanto ao tipo, natureza, origem e formatos sobre as características das informações para inteligência competitiva. Enfatizam que a inteligência competitiva é um processo de agregação de valor que envolve a coleta e disseminação das informações em todos os níveis da organização e que é vital a participação de profissionais qualificados e competentes.

Vieira (1999) focaliza a importância de um serviço de monitoração do ambiente da produção brasileira de informação científica e tecnológica com base nos Sistemas Estaduais de informação Científica e Tecnológica (Seict), como instrumento de macro-política, para constituição de 
indicadores de competitividade da Ciência e Tecnologia dos estados, com o objetivo de dar apoio a decisões, planejamento, acompanhamento e avaliação de desempenho às organizações governamentais e privadas. Apresenta a visão do que se passa em outros países, enfatizando a participação do Estado nas atividades de inteligência, em apoio ao setor produtivo.

Battaglia (1999) apresenta um estudo de caso sobre a Financiadora de Estudos e Projetos (Finep) que tem por missão fazer da ciência e tecnologia instrumentos para construir o futuro do Brasil, que necessita de um sistema de informação modelado para atender, ao mesmo tempo, os clientes que buscam financiamento e a sociedade/comunidade de Ciência e Tecnologia. Este estudo propõe um sistema de informação de clientes pautado nos componentes da inteligência competitiva, para que a empresa Finep desempenhe, cada vez melhor a sua missão de apoio financeiro à área de C\&T. Com a estruturação desse Sistema de Informações para Clientes, tornar-se-á, não só um instrumento de apoio à decisão nos vários níveis, assegurando a redução do tempo de resposta diante das demandas do ambiente interno e externo, assim como redução de custos, bem como representará para a sociedade uma valiosa fonte de informação. Esse trabalho é fruto da tese da autora.

Wanderley (1999) apresenta a concepção de um Sistema de Inteligência de Negócios (SIN), focalizando a Gerência de Investimentos de Engenharia na Indústria de petróleo, tendo como objetivo apoiar os processos decisórios do Serviço de Engenharia (Segen) da Petrobrás. Considera que a implantação de um sistema de inteligência de negócios, em alinhamento com o processo de planejamento do Segen, auxiliará este órgão a manter uma posição de excelência em relação ao mercado competitivo de gestão de investimentos de engenharia em nível mundial. Esta proposta é resultado da tese do autor.

Marco (1999) salienta que no cenário da competição, muito se tem discutido sobre as características da nova realidade econômica, principalmente no aspecto da dinâmica e da contextualidade. O conhecimento é cada vez mais um fator de competitividade. O desafio enfrentado é transformar informação em conhecimento antes que o ponto de decisão tenha passado. Os novos desafios da competição globalizada e a evolução rápida das novas tecnologias,

(C) Revista Digital de Biblioteconomia e Ciência da Informação, Campinas v.3, n. 1, p. 103-130, jul./dez. 2005 - ISSN: 1678-765X. 
obriga as empresas a repensar a forma como se mantêm vigilantes e capazes de se antecipar às mudanças.

Milani Junior (1999) apresenta um panorama da situação da BRASPETRO, subsidiária da Petrobrás, com anos de experiência no mercado internacional, que se ressente da falta de um sistema ágil e eficaz de planejamento e controle que dê suporte às suas necessidades de informação para a tomada de decisões relativas ao ambiente concorrencial. Considera que a inteligência competitiva pode ser a resposta para tais demandas. Neste artigo procurou oferecer formas de sincronizar a administração estratégica com a inteligência competitiva. Esperando, assim, estar contribuindo para o aperfeiçoamento dos sistemas de planejamento da BRASPETRO e da Petrobrás.

West (1999) considera a inteligência competitiva como uma disciplina formal. Mostra que o uso da inteligência competitiva na Europa foi estimulada pelo seu desenvolvimento nos EUA. Aponta que a inteligência competitiva consiste de especialistas em inteligência competitiva, investigadores de empresa, alimentadores de dados secundários, companhias benchmarking e organizações de pesquisa de mercado.

Miranda (1999) faz uma avaliação do uso de informações, em função de categorias definidas para as ações estratégicas implantadas pela Empresa Brasileira de Correios e Telégrafos (ECT). Com base na literatura revisada e dos resultados da pesquisa, propõe um modelo de sistemas de informações estratégicas para a ECT.

Coelho e Dou (1999/2000) discutem o contexto atual da sociedade da informação, a evolução da inteligência competitiva e da gestão do conhecimento. Apresenta a preocupação na formação de recursos humanos e a proposta da disseminação da inteligência competitiva no Brasil. Para esta formação de recursos humanos foi realizado curso de pós-graduação lato sensu conveniados com a Université Aix- Marseille, possibilitando aos alunos a construção de modelos próprios, por meio do conhecimento teórico, dos relatos de experiência e da prática. 
Stollenwerk (1999/2000) apresenta uma proposta genérica para a implantação de um sistema de inteligência competitiva nas organizações, dentro de uma visão corporativa, com a intenção de enriquecer o debate sobre inteligência competitiva entre pesquisadores, consultores e aos que já adotam soluções de inteligência competitiva em suas organizações. E, sobretudo, venha contribuir para a reflexão individual sobre o potencial de aplicação de inteligência competitiva no contexto de suas organizações e empresas.

Santos (1999/2000) enfatiza que o tomador de decisão precisa de informações relevantes, mas, antes de tudo, ele precisa de dispositivos de filtros, pois há uma gama de informações irrelevantes. Para isso a concepção de sistemas de gestão de informações estratégicas (SGIE), tem como um dos seus pressupostos, fornecer informações relevantes aos tomadores de decisão nas organizações. Mas, ainda assim, o acúmulo de informações é muito grande e a inserção de tecnologias de informação nas organizações parece ter contribuído para melhorar essa problemática. Para buscar informações úteis e críticas, exigem-se procedimentos cada vez mais otimizados, através de desenvolvimento de processos, metodologias e ferramentas, aliados ao conhecimento de fontes adequadas. O autor apresenta uma figura com o fluxo do processo de inteligência competitiva de acordo com a norma francesa AFNOR XP X50-053, onde apresenta a regulamentação para o processo de inteligência competitiva.

Moresi (1999/2000) apresenta conceitos de monitoração ambiental e inteligência organizacional, faz um paralelo com o paradigma da sociedade da informação. Salienta que o processo de transformação consiste no conhecimento, ferramentas e técnicas usadas para transformar entradas em saídas organizacionais, ou seja, insumos em produtos ou serviços. Ressalta que a fonte final de processamento de informação organizacional é a interpretação do ambiente externo. A organização, como um sistema aberto, não pode se fechar para o ambiente devendo ter mecanismos para aprender e interpretar eventos externos. Nesse sentido, o desenvolvimento da inteligência organizacional passa a assumir um papel fundamental para que a organização possa atender aos desafios dos componentes ambientais.

Araújo Junior e Cormier (1999/2000) abordam a utilização de informações transformadas em inteligência, a partir da adoção de estratégias do marketing de permissão, como forma de fidelizar 
clientes. O marketing de permissão se anuncia em um contexto caótico de multinformações, em que as pessoas são bombardeadas de todos os lados por fornecedores ávidos em vender produtos e serviços e não medem esforços para atingir essa meta. Para melhor ilustrar, apresentam o exemplo de uma empresa que emprega os recursos do marketing de permissão, é o caso da Amazon.com.

Baptista (1999/2000) apresenta o resultado de uma pesquisa que teve como universo nove entidades relacionadas aos setores: educação, indústria, setor bancário, trabalhadores, sindicatos, mulheres, cultura negra e consumidores. Visando a constatação da importância da opinião numa sociedade democrática, e ao mesmo tempo, de que formação de opinião não constitui função exclusiva da mídia. Partiu do pressuposto que as entidades representativas são formadores de opinião e que o acesso à informação é essencial ao formador de opinião. Os resultados permitiram concluir que a necessidade de credibilidade em relação à informação que se busca impõe a necessidade de algum tipo de registro. Portanto, foi negada a hipótese de que a comunicação informal é mais importante que as demais fontes de informação. Por outro lado, confirmou-se a hipótese de que há convergência quanto ao interesse predominante por uma tipologia da informação. A autora pretendeu com este estudo, contribuir ao entendimento da relação entre informação e opinião no contexto das entidades representativas e também ao entendimento de que, tal como ocorre em outros ambientes, nessas entidades a informação é um recurso a ser gerenciado em função do objetivo de cada instituição.

Robredo (1999/2000) apresenta de uma maneira sucinta, como a aplicação de princípios básicos da gestão por processos permite um novo enfoque do planejamento e gerência dos sistemas de informação e das práticas gerenciais aplicadas aos mesmos.

Roedel (1999/2000) apresenta um método para a definição de estratégias de negócio, a partir da articulação da sistemática de inteligência competitiva, com a criação de redes internas de conhecimento que atuem no sentido de aumentar a eficácia dos processos de planejamento estratégico. Salienta que a sistemática proposta para a definição de estratégias de negócios será de grande valia para que o SENAI/CETIQT amplie e consolide sua posição de Centro de Educação e

(C) Revista Digital de Biblioteconomia e Ciência da Informação, Campinas v.3, n. 1, p. 103-130, jul./dez. 2005 - ISSN: 1678-765X. 
Tecnologia para atendimento à cadeia Têxtil, cujas demandas vêm se modificando e intensificando, devido ao novo ambiente competitivo em que está inserida.

Moresi (2000) explora aspectos relativos ao valor da informação, buscando responder a questões sobre a finalidade da informação para uma organização, a classificação de seus tipos de valor e o seu valor econômico. Apresenta um conceito de informação, considerado mais adequado a esta abordagem, bem como os tipos de informação no contexto de uma organização. Salienta que os sistemas de informação têm sido desenvolvidos para otimizar o fluxo de informação relevante no âmbito de uma organização, desencadeando um processo de conhecimento e de tomada de decisão e intervenção na realidade.

Santos (2000) neste artigo reporta-se à problemática já abordada em referência acima citada de Santos (1999/2000).

Tarapanoff, Araújo Junior, Cormier (2000) discutem a atuação da unidade de informação no contexto da sociedade da informação, propondo a abordagem da inteligência competitiva para o monitoramento ambiental de informações e adequação organizacional. Dão destaque a algumas técnicas para o tratamento das informações, como a utilização de redes neurais, Data Warehousing, Data Mining. Citam como exemplo a experiência das atividades desenvolvidas no Centro de Quebec, no Canadá, assim como no Centro de Vigilância de Metais Leves (CVML). Salientam que os procedimentos adotados pela experiência relatada podem ser replicados em qualquer unidade de informação.

Silva (2001) analisa dimensões estratégicas da competitividade, em uma economia globalizada, para pequenas e médias empresas do setor de manufaturados. Procura destacar aspectos da qualidade, tecnologia, informação e meio ambiente. Foram consultados de 20 a 100 colaboradores de empresas de pequeno porte e de 100 a 500 colaboradores de empresas de médio porte, totalizando 90 empresas do Estado de São Paulo nos campos da qualidade e da tecnologia, a análise sempre respaldada na literatura. Como resultado, constata limitação em disponibilidade de conhecimentos, acesso a sistemas de informação e, por conseguinte, geração de conhecimentos para otimização organizacional nos campos da qualidade, gestão da tecnologia e 
gestão ambiental nos sistemas produtivos. Salienta que há necessidade das associações, órgãos de classe empresariais, universidades, promoverem conscientização das empresas brasileiras da importância da geração e gestão de conhecimentos para o seu desenvolvimento em campos estratégicos para a competitividade.

Moresi (2001) faz uma apresentação descritiva dos fatores que possibilitam desenvolver a inteligência no âmbito das organizações. Inicialmente, aborda a questão da gestão do conhecimento, onde são definidos os conhecimentos tácitos, explícitos e culturais. São discutidos, também, aspectos relativos às atividades que buscam desenvolver e controlar todo tipo de conhecimento em uma organização, visando à utilização na consecução de seus objetivos. $\mathrm{Na}$ conceituação de monitoração ambiental, foram incluídos a definição, os modos e alguns princípios de boas práticas. Aborda algumas considerações sobre inteligência organizacional. Define inteligência organizacional, além de distingui-la sob dois pontos de vista mutuamente dependentes: como um processo (dinâmico) e como um produto (estático). O autor conclui que o desenvolvimento da inteligência organizacional passa a assumir um papel fundamental para que a organização possa atender aos desafios dos componentes ambientais.

Santos e Beraquet (2001) procuram demonstrar que os profissionais de informação têm presença assegurada para desenvolver um papel muito importante, enquanto produtores de conhecimento, no momento que assumem uma postura estratégica de agentes sociais e privilegiam, nas suas formações, competências sobre o domínio e a rentabilização de fluxos de informação.

Canongia et al. (2001) apresentam metodologias e experiências de visão de futuro, monitoramento ambiental, inteligência competitiva e gestão do conhecimento como ferramentas de apoio ao processo decisório. Apresentam também uma proposta metodológica de sistema de informação estratégica como maior articulação e integração com os ambientes internos e externos e geração de conhecimento. Observam o quanto tem sido reforçada a necessidade de visão holística da organização como forma de melhor aproveitamento de suas competências, maior responsabilidade social e ambiental. 
Carvalho (2001) salienta que dada a necessidade de se obter informações cada vez mais rápidas, surgem novas tendências que objetivam recuperar a informação de forma acelerada. Considerando o ambiente das organizações, aonde mudanças vêm ocorrendo, motivadas pelos atuais padrões econômicos que visam contenção de custos, o uso das tecnologias de informação, assim como o relacionamento entre as pessoas torna-se mais frágil, e os ambientes mais adequados estão se estruturando, estimulando o compartilhamento. A disseminação assume um papel de grande valor no processo, porque, no fluxo da informação, para decidir e agir, ela necessita ser bem planejada, caso contrário, ela não circula e o processo não se completa.

Miranda (2001) apresenta a caracterização básica de um Sistema de Gerenciamento de Relacionamento com usuários (CRM), indicando suas fases, bem como um exemplo de implementação. Os CRMs vêm atuar como elos de ligação clientes, consumidores e empresas, permitindo que essas se organizem no sentido de aprimorar os seus serviços e produtos e a antecipar as necessidades de sua clientela. É nesse nicho que cabe a atuação do profissional da informação, que atuará na organização e classificação de todo o material coletado das demandas dos usuários. O profissional da informação será o mediador na busca de informações para os clientes e na geração de informações estratégicas e não estratégicas para a organização.

Jamil (2001) aborda sobre aspectos do ambiente gerencial e seus impactos no uso dos sistemas de inteligência competitiva para processos decisórios, e a importância da aplicação das chamadas ferramentas de inteligência competitiva, como o warehouses e data mining.

Silva (2002) expõe diversas visões ligadas à gestão do conhecimento, buscando entender o impacto deste tema na inovação dos processos organizacionais. Apresenta considerações sobre o valor do conhecimento para a competitividade empresarial. Apresenta também, uma imagem da organização como uma entidade constituída de processos orientados pelo conhecimento. Enfatiza questões relativas à aprendizagem, criatividade e a influência da tecnologia da informação neste processo. Salienta que a vantagem competitiva se manifesta mais notoriamente de duas formas, sendo a relação do conhecimento com a capacidade de inovar da empresa e a preparação e flexibilidade diante das mudanças no ambiente do mercado.

(C) Revista Digital de Biblioteconomia e Ciência da Informação, Campinas v.3, n. 1, p. 103-130, jul./dez. 2005 - ISSN: 1678-765X. 
Valentim (2002) enfatiza que o papel do conjunto, dados, informações e conhecimento, no processo de inteligência competitiva é fundamental para o aumento da produtividade e da qualidade da organização. Salienta que estabelecer fluxos formais e informais, bem como mapear e reconhecer os dados, informações e conhecimento estruturados, e não estruturados para o negócio, também são ações que contribuem para o desenvolvimento da inteligência competitiva organizacional.

Barbosa (2002) apresenta o resultado de uma pesquisa com a amostra de 91 participantes de cursos de especialização na área de administração em Belo Horizonte. Os participantes pertencem a empresas privadas nacionais e multinacionais, organizações do setor público, além de organizações de outras naturezas. Essas empresas atuam no setor da educação, informática, comércio e telecomunicações e outros setores. Com esta pesquisa buscou registrar dentre outros fatores, a freqüência com que esses participantes utilizam os diversos tipos de fontes de informação. Essas fontes foram analisadas de acordo com o seu grau de relevância e confiabilidade. Os resultados apontaram uma elevada taxa de utilização de fontes eletrônicas de informação, porém as mesmas são vistas como pouco confiáveis e relevantes. Os contatos pessoais são vistos como fontes mais confiáveis.

Silva (2003) apresenta uma proposta de um processo de inteligência competitiva na Internet que aplica agentes inteligentes na tarefa de monitoramento das fontes de informação consideradas estratégicas por organizações de qualquer tipo, que estão disponíveis na rede. Esse processo foi testado em quatro estudos de caso, sendo na Digitro Tecnologia Ltda., empresa catarinense da área de telecomunicações, na Associação Catarinense de Empresas de Tecnologias (Acate) e no Laboratório de Controle de Processos (LTC), vinculado ao Departamento de Química da Universidade Federal de Santa Catarina, como piloto testou-se no Núcleo de Estudos em Inovação, Gestão e Tecnologia de Informação (IGTI), vinculado ao Programa de Pós-graduação em Engenharia de Produção da Universidade Federal de santa Catarina. Entre outras considerações apontadas, a autora infere que a maioria das organizações ainda não se insere no paradigma de organizações que têm como base à informação e em conseqüência disso, no conceito de organização de aprendizagem.

(C) Revista Digital de Biblioteconomia e Ciência da Informação, Campinas v.3, n. 1, p. 103-130, jul./dez. 2005 - ISSN: 1678-765X. 
Silveira (2003) identifica, classifica e analisa as motivações e os fatores críticos de sucesso a ser considerados no processo de planejamento de sistemas de informação entre várias organizações, evidenciando a oferta de informações e serviços públicos, via Internet. O autor apresenta um estudo de caso em 14 órgãos públicos com área de atuação relacionada com temas de interesse do Banco Central e vinculação hierárquica ao Ministério da Fazenda. Como conclusão registra que a decisão de implementar sistemas interorganizacionais significa uma quebra de paradigma, por afastar-se da forma tradicional de gerenciamento de sistemas e passar a conviver com os benefícios (e riscos) do modelo colaborativo, com outros limites e novas regras.

Barreto (2003) apresenta os resultados de uma pesquisa sobre as 'Políticas de monitoramento da informação por compressão e semântica dos seus estoques'. Esse estudo se orienta para a análise da estrutura do texto escrito e sua análise morfológica com a finalidade de extrair informações tanto para uso na gestão estratégica da informação, localizada em estoques específicos, como para fornecer subsídios para a construção de instrumental de monitoração de textos em língua portuguesa e outros estudos onde um agente de software desta natureza seja necessário. Paralelamente procura fornecer subsídios técnicos e teóricos para construção de agentes indispensáveis ao controle do cenário atual em diferentes contextos informacionais. Salienta que quanto aos softwares já disponibilizados comercialmente, trazem problemas, como: a) são elaborados para um estudo específico de um determinado pesquisador e não atendem à necessidade de outro estudo específico; b) seu desenvolvimento se direciona para a língua para a qual haviam sido programados, não reconhecendo particularidades do português, tais como acentuação e cedilha; c) grande parte destes instrumentos haviam sido projetados para análise literária, como poesia e ficção, e não suportam adequadamente a literatura de ciência e tecnologia. Assim está em desenvolvimento um software para atender estas especificidades, esse instrumento está denominado de Protexto.

Cândido e Araújo (2003) mostram como uma ferramenta de tecnologia da informação pode contribuir para a viabilização da prática da inteligência competitiva e da gestão do conhecimento em um setor específico de uma organização, tornando-a mais flexível, ágil e adaptável. Neste trabalho foi utilizado o software Personal Brain, uma ferramenta a qual permite mapear os fluxos e os inter-relacionamentos das informações internas e externas à organização. O software 
mencionado foi aplicado no departamento de recursos humanos de uma secretaria em uma prefeitura municipal.

Canongia et al. (2004) apresentam a produção científica internacional em Inteligência competitiva e Gestão do conhecimento aplicadas ao setor da Saúde. Selecionaram os artigos indexados em três bases do ISI Web of Science, utilizando as bases do Science Citation Index Expanded (Scle), Social Science Citation Index (SSCI) e Arts \& Humanities Citattion Index (A\&HCI), no período 1990/2003. São apresentados mapas de conhecimento decorrentes de text mining, para análise da evolução de publicação, identificação de instituições, parcerias e análises de conteúdo para verificação dos enfoques adotados.

Hoffmann, Gregolin, Oprime (2004) destacam a contribuição da inteligência competitiva para o desenvolvimento de Arranjos Produtivos Locais (APLs) ou Clusters, apresentando um estudo de caso no Pólo Calçadista de Jaú- SP, onde foi aplicada a análise estatística de cluster através do software Statistica. Procuraram estudar a interatividade do território, entender o processo de inovação que se desenvolve, identificar gargalos tecnológicos e caracterizar a dinâmica produtiva local. Procurou mostrar que é possível encontrar ferramentas úteis para os estudos de APLs.

Miquelino, Santos, Padovani (2004) descrevem um estudo de caso realizado no Centro de Pesquisa e Desenvolvimento em Telecomunicações (CPqD) sobre a inteligência competitiva aplicada à comunicação e arquitetura da marca de uma organização. Mostram uma aplicação prática dos conceitos caracterizados pela administração baseados na marca da empresa, branding.

Valentim e Molina (2004) apresentam alguns métodos e técnicas de prospecção e monitoramento informacional no processo de inteligência competitiva. Salientam a importância das tecnologias da informação e comunicação para a prospecção e monitoramento informacional, onde comentam sobre o Data Mart, Data Warenhouse, Data Mining e os Sistemas de Informações ExecutivasExecutive Information Systems (E.I.S.) Enfatizam que a tecnologia da informação é a ferramenta de apoio a prospecção e ao monitoramento, e o homem é o responsável pelo conhecimento a ser agregado nas várias etapas que compõem essas atividades.

(C) Revista Digital de Biblioteconomia e Ciência da Informação, Campinas v.3, n. 1, p. 103-130, jul./dez. 2005 - ISSN: 1678-765X. 
Tarapanoff (2004) aborda os conceitos de inteligência social e coletiva no contexto da Sociedade da Informação e do Conhecimento. Apresenta o desenvolvimento da inteligência econômica nos países e a aplicação da inteligência competitiva nas organizações. Defende que as ações conjuntas do processo de gestão da informação e gestão do conhecimento são pontos estratégicos para o processo de tomada de decisão nas organizações.

Valentim e Woida (2004) abordam sobre a cultura organizacional no processo de inteligência competitiva, como algo que pode ser construído visando alianças estratégicas, entre as pessoas e a organização. A cultura organizacional é fundamental para que a I.C. possa ser de fato uma realidade, pois possibilita uma dinâmica positiva à consolidação da ética convencionada pela organização, estabelecendo princípios, valores e crenças essenciais para a inteligência competitiva.

\section{CONSIDERAÇÕES FINAIS}

Observou-se que inteligência competitiva é um tema que vem sendo tratado sob diferentes abordagens: como o uso da Internet, excesso de informações, processo de coleta da informação formal, informal, automatizada, personalizada, métodos, técnicas e ferramentas para análise e monitoramento da informação, e principalmente da exigência da intervenção humana, no tratamento da informação. Com as constantes mudanças que ocorrem no ambiente competitivo, as decisões são tomadas em espaços de tempo cada vez mais curtos. Daí a necessidade de se dispor de um sistema capaz de fornecer informações previamente analisadas, aí é que se encontra o diferencial, assegurando a tomada de decisão na hora certa.

A partir de 1999 houve uma maior preocupação em passar a divulgar mais sobre o assunto e principalmente enfocar a importância do papel do profissional da informação bibliotecário. Assim o próprio profissional da informação passou a pesquisar e divulgar sobre a influência deste agente inteligente, catalisador e mediador no processo de integração da inteligência competitiva como tomador de decisão.

(C) Revista Digital de Biblioteconomia e Ciência da Informação, Campinas v.3, n. 1, p. 103-130, jul./dez. 2005 - ISSN: 1678-765X. 
Concluí-se que um analista inteligente deve ter não apenas a habilidade em recuperar a informação, mas deve organizar dados e fatos de muitas fontes, ver tendências, anomalias e descobrir relações significativas para chegar a descobertas e conclusões que agreguem valor à organização.

\section{REFERÊNCIAS}

ABREU, Aline França de; FRANÇA, Thamara da Costa Vianna; SINZATO, Carmen Isabel Pereira. Acesso à informação: promovendo competitividade em P\&D com o uso da tecnologia de informação. Ciência da Informação, Brasília, v. 28, n. 3, p. 322-332, set./dez. 1999.

ARAUJO JUNIOR, Rogério Henrique de; CORMIER, Patrícia Marie Jeanne. Inteligência em marketing: o marketing de permissão como ferramenta para a fidelização de clientes. R. Bibliotecon. Brasília, Brasília, v. 23/24, n. 4, p. 527-544, 1999/2000. Edição especial.

BAPTISTA, Dulce Maria. A busca da informação por parte de entidades representativas enquanto formadoras de opinião: um problema gerencial. R. Bibliotecon. Brasília, Brasília, v. 23/24, n. 4, p. 545-550, 1999/2000. Edição especial.

BARBOSA, Ricardo Rodrigues. Inteligência Empresarial: uma avaliação de fontes de informação sobre o ambiente organizacional externo. DataGramaZero - Revista de Ciência da Informação, Rio de Janeiro, v. 3, n. 6, dez. 2002. Disponível em:<http://www.dgz.org.br>. Acesso em: 20 de março de 2003.

BARRETO, Aldo de Albuquerque. Políticas de monitoramento da informação por compressão e semântica dos seus estoques. DataGramaZero - Revista de Ciência da Informação, Rio de Janeiro, v. 4, n. 2, abr. 2003. Disponível em:<http://www.dgz.org.br>. Acesso em: 15 dez. 2003.

BATTAGLIA, Maria da Glória Botelho.A inteligência competitiva modelando o sistema de informação de clientes: Finep. Ciência da Informação, Brasília, v. 28, n. 2, p.200-214, maio/ago.1999 .

CÂNDIDO, Gesinaldo Ataíde; ARAÚJO, Nadja Macêdo de. As tecnologias de informação como instrumento de viabilização da gestão do conhecimento através da montagem de mapas cognitivos. Ci. Inf., Brasília, v. 32, n. 3, set./dez. 2003. Disponível em: <http://www.scielo.br>. Acesso em: 19 nov. 2004.

(C) Revista Digital de Biblioteconomia e Ciência da Informação, Campinas v.3, n. 1, p. 103-130, jul./dez. 2005 - ISSN: 1678-765X. 
CANONGIA, Claudia; LAMB, Celina; CARVALHO, Cátia Silene de P.; SILVA, Valdenis Souza e. Convergência da inteligência competitiva com construção de visão de futuro: proposta metodológica de Sistema de Informação Estratégica (SIE). DataGramaZero - Revista de Ciência da Informação, Rio de Janeiro, v. 2, n. 3, jun. 2001. Disponível em: $<$ http://www.dgz.org.br>. Acesso em: 20 mar. 2003.

; PEREIRA, Maria de Nazaré F.; MENDES, Cristina d'Urso de Souza; ANTUNES, Adelaide. Mapeamento de inteligência competitiva (IC) e de gestão do conhecimento (GC) no setor saúde. Enc. Bibli: R. Eletr. Bibliotecon. Ci. Inf., Florianópolis, 1 sem. 2004. Edição especial. Disponível em: <http://www.encontros-bibli.ufsc.br/>. Acesso em: 14 nov. 2004.

CARVALHO, Kátia de. Disseminação da informação e informação de inteligência organizacional. DataGramaZero - Revista de Ciência da Informação, Rio de Janeiro, v. 2, n. 3, jun. 2001. Disponível em:<http://www.dgz.org.br>. Acesso em: 20 de março de 2003.

COELHO, Gilda Massari; DOU, Henri. Inteligência competitiva e a formação de recursos humanos no Brasil. R. Bibliotecon. Brasília, Brasília, v. 23/24,n. 4, p. 455-472, 1999/2000. Edição especial.

COMBS, Richard E.; MOORHEAD, Jonh D. The competitive intelligence handbook. Chicago: Scarecrow Press, 1993.

COSTA, Marília Damiani; SILVA, Iranise Alves da. Inteligência competitiva: uma abordagem sobre a coleta de informações publicadas. Informação \& Sociedade: Estudos, João Pessoa, v. 9, n.1, p. 11-28, 1999.

CUBILLO, Julio. La inteligencia empresarial en las pequenãs y medianas empresas competitivas de América Latina: algunas reflexiones. Ciência da Informação, Brasília, v. 26, n. 3, p. 260-267, set./dez.1997.

FREEMAN, Olívia. Competitor intelligence: information or intelligence? Business Information Review, London, v. 16, n. 2, p. 71-76, June,1999.

HOFFMANN, Wanda A. M.; GREGOLIM, José A. R.; OPRIME, Pedro C. A contribuição da inteligência competitiva para o desenvolvimento de arranjos produtivos locais: caso Jaú-SP. Enc. Bibli: R. Eletr. Bibliotecon. Ci. Inf., Florianópolis, 1 sem. 2004. Edição especial. Disponível em: $<$ http://www.encontros-bibli.ufsc.br/>. Acesso em: 14 nov. 2004.

JACOBIAK, François. Pratique de la veille technologique. Paris: Éditions d'Organisation, 1996.

JAMIL, George Leal. Aspectos do ambiente gerencial e seus impactos no uso dos sistemas de inteligência competitiva para processos decisórios. Perspect. cienc. inf., Belo Horizonte, v. 6, n. 2, p. 261-274, jul./dez. 2001.

(C) Revista Digital de Biblioteconomia e Ciência da Informação,Campinas v.3, n. 1, p. 103-130, jul./dez. 2005 - ISSN: 1678-765X 
KAHANER, Larry. Competitive intelligence. New York : Simon \& Schuster, 1996.

MARCO, Sueli Aparecida. Inteligência competitiva: definições e contextualização. Transinformação, Campinas, v. 11, n. 2, p. 95-102, maio/ago.1999.

MARTINET, Bruno; MARTI, Yves-Michel. L'intelligence économique: les yeux et les oreilles de l'entreprise. Paris: Les Éditions de l'Organisation, 1995.

MAURY, Patrick. Inteligência competitiva e decisão empresarial. Ciência da Informação, Brasília, v. 22, n. 2, p.138-141, maio/ago. 1993.

MILANI JUNIOR, Angelo. Base conceitual para implantação de um sistema de inteligência competitiva na BRASPETRO. Transinformação, Campinas, v. 11, n. 2, p.79-93, maio/ago.1999.

MIQUELINO, Fernando L. C.; SANTOS, Raimundo N. M.; PADOVANI, Reginaldo C. A inteligência competitiva aplicada à comunicação e à arquitetura da marca de uma organização. Enc. Bibli: R. Eletr. Bibliotecon. Ci. Inf., Florianópolis, 1 sem. 2004. Edição especial. $<$ http://www.encontros-bibli.ufsc.br/>. Acesso em: 14 nov. 2004.

MIRANDA, Roberto Campos da Rocha. Fonte de informação estratégica e não estratégica: Costumer Relationship Management. DataGramaZero - Revista de Ciência da Informação, Rio de Janeiro, v. 2, n. 3, jun. 2001. Disponível em: $<$ http://www.dgz.org.br $>$. Acesso em: 20 mar. 2003.

- O uso da informação na formulação de ações estratégicas pelas empresas. Ciência da Informação, Brasília, v. 28, n. 3, p. 286-292, set./dez. 1999.

MORESI, Eduardo Amadeu Dutra. Delineando o valor do sistema de informação de uma organização. Ciência da Informação, Brasília, v. 29, n. 1, p. 14-24, jan./abr. 2000.

- Inteligência organizacional: um referencial integrado.

Ciência da Informação, Brasília, v.30, n. 2, p. 35-46, 2001.

MORESI, Eduardo Amadeu Dutra. Inteligência organizacional no contexto da sociedade da informação. R. Bibliotecon. Brasília, Brasília, v. 23/24, n. 4, p. 509-526, 1999/2000. Edição especial.

NAISBITT, John; ABURDENE, Patrícia. Re-inventing the corporation. New York: Warner Books, 1985.

PORTER, Michael. Estratégia competitiva: técnicas para análise de indústrias e da concorrência. Rio de Janeiro: Campus, 1986.

(C) Revista Digital de Biblioteconomia e Ciência da Informação, Campinas v.3, n. 1, p. 103-130, jul./dez. 2005 - ISSN: 1678-765X. 
POZZEBON, Marlei; FREITAS, Henrique M. R. de; PETRINI, Maira. Pela integração da inteligência competitiva nos Enterprise Information Systems (EIS). Ciência da Informação, Brasília, v. 26, n. 3, set./dez. 1997. Disponível em: <http:// www.ibict.com.br/cionline>. Acesso em: 25 abr. 2003.

PRAHALAD, C. K.; KRISHNAM, M.S. The new meaningof quality in the information age. Harvard Business Review, v. 77, n. 5, p. 109-118, Sept.1999.

ROBREDO, Jaime. Planejamento e gerência de sistemas de informação sob o ângulo da gestão por processos. R. Bibliotecon. Brasília, Brasília, v. 23/24, n. 4, p. 551-558, 1999/2000. Edição especial.

ROEDEL, Daniel. Inteligência competitiva na cadeia têxtil. R. Bibliotecon. Brasília, Brasília, v. 23/24, n. 4, p.559-564, 1999/2000. Especial.

SANTOS, Raimundo Nonato Macedo dos; Beraquet, Vera Silva Marão. Informação estratégica e empresa: o discurso à prova dos fatos. DataGramaZero - Revista de Ciência da Informação, Rio de Janeiro, v. 2, n. 3, jun. 2001. Disponível em:<http://www.dgz.org.br $>$. Acesso em: 20 mar. 2003.

- Métodos e ferramentas para gestão de inteligência e do conhecimento. Perspect. cienc. inf., Belo Horizonte, v. 5, n. 2, p. 205-215, jul./dez.2000.

- Processos, métodos e ferramentas de inteligência competitiva: características, aplicabilidade e limitações. R. Bibliotecon. Brasília, Brasília, v. 23/24, n. 4, p.493-508, 1999/2000. Especial.

SILVA, Eduardo Orozco. La inteligencia organizacional en la industria biofarmacéutica. Ciência da Informação, Brasília, v. 28, n. 1, p. 59-66, jan./abr.1999.

SILVA, Helena Pereira das. Inteligência competitiva na Internet: um processo otimizado por agentes inteligentes. Ciência da Informação, Brasília, v. 32, n. 1, p. 115-134, jan./abr. 2003.

SILVA, José Carlos Teixeira da. Dimensões de competitividade para a empresa brasileira: informação e conhecimento, qualidade, tecnologia e meio ambiente. Transinformação, Campinas, v. 13, n. 2, p. 81-92, jul./dez.2001.

SILVA, Sérgio Luis da. Informação e competitividade: a contextualização da gestão do conhecimento nos processos organizacionais. Ciência da Informação, Brasília, v. 31, n. 2, p. 142-151, maio/ago.2002.

SILVEIRA, Henrique Flávio Rodrigues da. Motivações e fatores de sucesso para o planejamento de sistemas interorganizacionais na sociedade da informação. Ciência da Informação, Brasília, v. 32, n. 2, p. 107-124, maio/ago. 2003.

(C) Revista Digital de Biblioteconomia e Ciência da Informação, Campinas v.3, n. 1, p. 103-130, jul./dez. 2005 - ISSN: 1678-765X. 
SIMMONS, David. Competitor intelligence-can you manage without it? Business Information Review, London, v. 14,n. 4, p. 173-177, Dec.1997.

STOLLENWERK, Maria de Fátima. Implantação de sistemas de inteligência competitiva: abordagem corporativa. R. Bibliotecon. Brasília, Brasília, v. 23/24, n. 4, p. 473-492, 1999/2000. Edição especial.

TARAPANOFF, Kira. Inteligência social e inteligência competitiva. Enc. Bibli: R. Eletr. Bibliotecon. Ci. Inf., Florianópolis, 1 sem. 2004. Disponível em: <http://www.encontrosbibli.ufsc.br/>. Acesso em: 14 nov. 2004.

; ARAÚJO JÚNIOR, Rogério Henrique de; CORMIER, Patricia Marie Jeanne. Sociedade da informação e inteligência em unidades de informação. Ciência da Informação, Brasília,v. 29, n. 3, p. 91-100, set./dez.2000.

TARAPANOFF, Kira (Org.). Inteligência organizacional e competitiva. Brasília: Ed. da UnB, 2001.

TOMIMORI, Sonia Maria Akiko Wada. A inteligência competitiva e a área de informação tecnológica no Instituto de Pesquisas Tecnológicas do Estado de São Paulo S.A. Ciência da Informação, Brasília, v. 28, n. 1, p. 89-93, jan./abr.1999.

TUDOR-SILOVIC, Neva. Inteligência como recurso social e empresarial. Informação \& Sociedade: Estudos, João Pessoa, v. 2, n.1, p.124-140, 1992.

TYSON, Kirk W.M. The complete guide to competitive intelligence: gathering, analyzing and using competitive intelligence. Chicago: Kirk Tyson International, 1998.

VALENTIM, Marta Lígia Pomim. Inteligência competitiva em organizações: dado, informação e conhecimento. DataGramaZero - Revista de Ciência da Informação, v. 3, n. 4, ago. 2002. Disponível em:<http://www.dgz.org.br>. Acesso em: 20 mar. 2003.

; MOLINA, Letícia Gorri. Prospecção e monitoramento informacional no processo de inteligência competitiva. Enc. Bibli: R. Eletr. Bibliotecon. Ci. Inf., Florianópolis, 1 sem. 2004. Edição especial. Disponível em: <http://www.encontrosbibli.ufsc.br/>. Acesso em: 14 nov. 2004.

; WOIDA, Luana Maria. Cultura organizacional no processo de inteligência competitiva. DataGramaZero - Revista de Ciência da Informação, v. 5, n. 4, ago. 2004. Disponível em:<http://www.dgz.org.br>. Acesso em: 20 mar. 2003.

VIEIRA, Anna da Soledade. Monitoração da competitividade científica e tecnológica dos estados brasileiros: um instrumento de macropolítica de informação. Ciência da Informação, Brasília, v. 28, n. 2, p. 174-189, maio/ago.1999. 
WANDERLEY, Ana Valéria Medeiros. Um instrumento de macropolítica de informação: concepção de um sistema de inteligência de negócios para gestão de investimentos em engenharia. Ciência da Informação, Brasília, v. 28, n. 2, p. 190-199, maio/ago.1999.

WEST, Chris. Competitive intelligence in Europe. Business Information Review, London, v. 16, n. 3, p. 143-150, Sept. 1999.

\section{ESTERA MUSZKAT MENEZES}

Professora do Departamento de Ciência da Informação da Universidade Federal de Santa Catarina. e-mail: estera@cin.ufsc.br Fone ( xx 48) 3319304

Artigo aceito para publicação em: 07/ 2005 